\title{
Distinguishing Hope and Optimism: Two Sides of a Coin, or Two Separate Coins?
}

Fred B. Bryant

Loyola University Chicago, fbryant@luc.edu

Jamie A. Cvengros

University of lowa

Follow this and additional works at: https://ecommons.luc.edu/psychology_facpubs

Part of the Psychology Commons

\section{Recommended Citation}

Bryant, Fred B. and Cvengros, Jamie A.. Distinguishing Hope and Optimism: Two Sides of a Coin, or Two Separate Coins?. Journal of Social and Clinical Psychology, 23, 2: 273-302, 2004. Retrieved from Loyola eCommons, Psychology: Faculty Publications and Other Works, http://dx.doi.org/10.1521/

jscp.23.2.273.31018

This Article is brought to you for free and open access by the Faculty Publications and Other Works by Department at Loyola eCommons. It has been accepted for inclusion in Psychology: Faculty Publications and Other Works by an authorized administrator of Loyola eCommons. For more information, please contact ecommons@luc.edu. (c) (i) $\Theta \Theta$

This work is licensed under a Creative Commons Attribution-Noncommercial-No Derivative Works 3.0 License. (c) Guilford Press, 2004. 


\title{
DISTINGUISHING HOPE AND OPTIMISM: TWO SIDES OF A COIN, OR TWO SEPARATE COINS?
}

\author{
FRED B. BRYANT \\ Loyola University Chicago \\ JAMIE A. CVENGROS \\ University of lowa
}

\begin{abstract}
Structural equation modeling was used to test hypotheses about (a) the dimensionality of measures of dispositional hope (the Adult Hope Scale, AHS) and dispositional optimism (the Life Orientation Test, LOT), (b) the extent and source of conceptual overlap and divergence between hope and optimism, and (c) patterns of discriminant validity for each trait. Separate two-factor models best fit the hope (Agency and Pathways, $r=$ .68) and optimism (Optimism and Pessimism, $r=-.63$ ) data. Analyzing the combined AHS and LOT data, a measurement model with separate, correlated second-order factors of Hope and Optimism $(r=.80)$ provided a better fit than did a higher-order model with a single second-order factor. Optimism correlated equally with both Agency and Pathways, whereas Pessimism was more strongly correlated with Agency than with Pathways. Confirming hypotheses, second-order Optimism had a stronger influence on the use of positive reappraisal as a coping strategy than did second-order Hope, whereas second-order Hope had a stronger influence on level of general self-efficacy than did second-order Optimism. We suggest that hope focuses more directly on the personal attainment of specific goals, whereas optimism focuses more broadly on the expected quality of future outcomes in general.
\end{abstract}

A sailor without a destination cannot hope for a favorable wind.

- Leon Tec

\footnotetext{
The authors wish to thank Ron Johnson for help in data collection, and Merrilee Bryant, Evelyn Perloff, and Robert Russell for helpful comments on an earlier draft of this manuscript. We are also indebted to Rick Snyder and three anonymous reviewers for their insightful editorial suggestions.

Please address all correspondence concerning this manuscript to: Dr. Fred B. Bryant, Department of Psychology, Loyola University Chicago, 6525 North Sheridan Road, Chicago, Illinois, 60626; E-mail: fbryant@luc.edu.
} 
A pessimist sees the difficulty in every opportunity; an optimist sees the opportunity in every difficulty.

- Sir Winston Churchill

The recent emergence of positive psychology as an integrative research domain (Seligman \& Csikszentmihalyi, 2000) has sparked new interest in understanding basic domains of positive subjective experience. Over the years, previous researchers have developed a variety of different theoretical perspectives on the central concepts that form the bedrock of positive psychology, including models of self-actualization (Maslow, 1970), hardiness (Kobasa, 1979), subjective well-being (Diener, 1984), flow (Csikszentmihalyi, 1990), learned optimism (Seligman, 1991), and hope (Meninger, 1959). Yet there remains little consensus as to what these core theoretical constructs are, how they should be defined, and how they relate conceptually to one another. If positive psychology is to advance, however, its core concepts must be explicated clearly and precisely, and the conceptual and operational commonalities and uniquenesses among these key constructs must be clarified.

As a case in point, consider hope and optimism, two central concepts in positive psychology. How should we best conceptualize these terms? Are hope and optimism separate constructs, or do they reflect the same global underlying trait? If hope and optimism are distinct, then how closely related are they, and in what ways are they similar or different? The present research addresses these basic questions with three main goals: (a) to identify the conceptual dimensions underlying hope and optimism, (b) to determine the degree of conceptual overlap between hope and optimism, and (c) to evaluate evidence of discriminant validity for each trait. The present study focused exclusively on dispositional forms of hope and optimism. We thus defined these two constructs as personality traits as opposed to cognitive or emotional states. Although a state measure of hope exists (see Snyder et al., 1996), it reflects a different form of the target construct from what we are measuring.

In the following sections, we first briefly review past conceptual and empirical work on optimism and hope, and then use this prior work to develop research hypotheses about the structure of each concept. We next consider the relationship between optimism and hope, drawing on the existing literature to derive hypotheses about ways in which the two traits are alike and ways in which they are different. Finally, we address the conceptual issue of discriminant validity-i.e., whether hope and optimism show a different pattern of relationships with important criterion variables-and we make specific hypotheses about divergent patterns of association between the two traits. 


\section{THE MEANING AND MEASUREMENT OF DISPOSITIONAL OPTIMISM}

Individual differences in future orientation are a component of many different theoretical frameworks, including models of depression (Beck, 1967), subjective well-being (Bryant \& Veroff, 1984), and generalized outcome expectancies (Rotter, 1954). Probably the most widely studied of these future-focused traits is optimism (see Chang, 2001; Gillham, 2000), with the most dominant theoretical perspective arguably being Scheier and Carver's (1985) conception of dispositional optimism as generalized outcome expectancies. Although numerous other models of optimism have been developed (e.g., Colligan, Offord, Malinchoc, Schulman, \& Seligman, 1994; Dember et al., 1989; Levy, 1985; Malinchoc, Offord, \& Colligan, 1995), we adopted Scheier and Carver's (1985) model because it is has the strongest evidence of construct validity and is the most widely used.

In their original formulation, Scheier and Carver (1985) defined optimism as a stable predisposition to "believe that good rather than bad things will happen" (p. 219). Thus, dispositional optimism was originally conceptualized as a unitary trait representing a single bipolar continuum, with optimism at one end of the spectrum and pessimism at the other. One way through which optimism is hypothesized to influence psychological and physical well-being is by predisposing individuals to engage in positive reinterpretation as a style of coping-i.e., "putting problems in the best possible light and searching for hidden benefits and meaning when difficulties arise" (Scheier, Carver, \& Bridges, 1994, p. 1072).

To assess dispositional optimism, Scheier and Carver (1985) constructed the Life Orientation Test (LOT) consisting of four statements designed to reflect optimism (e.g., "In uncertain times, I usually expect the best"; "I'm always optimistic about my future"), four statements designed to reflect pessimism (e.g., "If something can go wrong for me, it will"; "I rarely count on good things happening to me"), and four unscored "filler" items, with which respondents indicate their extent of agreement. A large body of evidence supports the reliability and validity of the LOT as a measure of dispositional optimism, and links optimism to a variety of psychological and physical outcomes (see Scheier \& Carver, 1992). Although some critics (e.g., Smith, Pope, Rhodewalt, \& Poulton, 1989) have argued that the LOT is better conceptualized as a measure of neuroticism rather than optimism, more recent evidence supports the discriminant validity of the LOT as distinct from general negative affectivity (e.g., Bryant \& Baxter, 1997; Mroczek, Spiro, Aldwin, Ozer, \& Bosse, 1993; Scheier et al., 1994). Indeed, the LOT has far more 
evidence supporting its construct validity and cross-sample generalizability than does any other existing measure of optimism.

Subsequent work has led to the refinement of this instrument. For example, Scheier et al., 1994) identified two LOT items that seem explicitly to reflect positive reinterpretation as a coping strategy (i.e., "I always look on the bright side of things," and "I'm a believer in the idea that 'every cloud has a silver lining'"), rather than the expectation of positive outcomes per se. Including these two problematic items in the LOT might inflate the apparent relationship between optimism and positive reinterpretation (Affleck \& Tennen, 1996). To remedy this problem, Scheier et al. (1994) proposed a "minor modification" (p. 1063) of the LOT, in which these two items and one pessimism item ("Things never work out the way I want them to") are omitted, and one optimism item ("Overall, I expect more good things to happen to me than bad") is added, yielding three measures of optimism and three measures of pessimism. Supporting the use of this revised instrument (i.e., LOT-R), Scheier et al. (1994) reported a Cronbach's $\alpha$ of .78 for the new six-item total score, with relatively stable test-retest correlations at four months (.68), one year (.60), and two years (.56). Scheier et al. (1994) further suggested that the original and revised versions of the instrument are essentially comparable, based on high correlations ("in the .90 s," p. 1073) between total scores on the LOT and LOT-R.

A Bidimensional Model of Optimism. Although Scheier and Carver (1985) originally conceptualized optimism as a global unidimensional trait, other work suggests that dispositional optimism consists of two separate subtraits reflecting positively-framed optimism and negatively-framed pessimism. To explain discrepancies in outcome expectancies within individuals, for example, Dember, Martin, Hummer, Howe, and Melton (1989) proposed a bidimensional model of optimism, in which people have both a level of optimism and a level of pessimism. Within this theoretical perspective, the rejection of pessimism is not the same as the endorsement of optimism; nor is the rejection of optimism equivalent to the endorsement of pessimism.

Empirical research supports this two-factor model, though there remains disagreement as to how intercorrelated optimism and pessimism are. Using confirmatory factor analysis to investigate the responses of 389 college students to the LOT, for example, Chang, D'Zurilla, and Maydeu-Olivares (1994) found that a model consisting of correlated (i.e., oblique) dimensions of optimism and pessimism $(r=-.54)$ fit the data better than did a one-factor "total score" model. Indeed, Scheier and Carver's (1985) factor analyses of their own LOT data revealed two moderately correlated ( $r=-.64)$ factors, Optimism and Pessimism, which together fit their data significantly better than did a one-factor 
model. Affleck and Tennen (1996) also concluded that the LOT taps two separate factors, but argued that optimism and pessimism are "relatively orthogonal constructs" (p. 909). Research with children (Fischer \& Leitenberg, 1986) and older adults (Mroczek et al., 1993; Robinson-Whelen, Kim, MacCallum, \& Kiecolt-Glaser, 1997) supports a bidimensional, as opposed to unidimensional, model of dispositional optimism. There is also evidence to support the discriminant validity of this bidimensional structure in predicting mood (Marshall, Wortman, Kusulas, Hervig, \& Vickers, 1992) and physical health (Robinson-Whelen et al., 1997). In the present study, we tested the hypothesis that a two-factor model that distinguishes between correlated dimensions of Optimism and Pessimism explains responses to the LOT better than does a one-factor model, we examined the strength of the relationship between optimism and pessimism, and we evaluated the discriminant validity of optimism and pessimism factors in predicting coping and self-efficacy.

\section{THE MEANING AND MEASUREMENT OF DISPOSITIONAL HOPE}

Related to the notion of optimism, and sharing some of the same conceptual features (see Snyder, Sympson, Michael, \& Cheavens, 2001), is the concept of hope. A handful of theoretical models have stimulated the bulk of empirical research on hope. However, "the predominant perspective on hope in the research literature is Snyder's cognitive conceptualization (e.g., Snyder, Harris, et al., 1991)" (Kwon, 2002, p. 208). Within this framework, hope is defined as "a cognitive set that is based on a reciprocally derived sense of successful (a) agency (goal-directed determination) and (b) pathways (planning of ways to meet goals)" (Snyder et al., 1991, p. 571). Within this two-factor framework, agency refers to a sense of efficacy (or "will") in working toward one's goals, and pathways refers to the development of plans (or "ways") to achieve desired goals (see also Snyder, 1989, 1994, 1995, 2000, in press).

To assess dispositional hope, Snyder et al. (1991) developed the Adult Hope Scale (AHS), consisting of four statements designed to reflect agency (e.g., "I energetically pursue my goals"; "I meet the goals I set for myself"), four statements designed to reflect pathways (e.g., "I can think of many ways to get out of a jam"; "There are lots of ways around any problem"), and four unscored "filler" items, with which respondents indicate their extent of agreement. A growing body of evidence supports the reliability and validity of the AHS as a measure of dispositional hope, and connects hope to a host of psychological and physical variables (see Snyder, in press; Snyder et al., 2001). The AHS has more evi- 
dence supporting its construct and external validity than does any other measure of dispositional hope.

Empirical research supports Snyder et al.'s (1991) bidimensional model of hope. Factor analyses of the AHS have revealed two distinct factors reflecting agency and pathways that are positively correlated, with the typical magnitude of correlation being about .40 (Snyder et al., 2001). Consistent with the notion of correlated factors, confirmatory factor analyses have shown that responses to the AHS are accurately represented in terms of an overarching higher-order hope construct defined by the agency and pathways subtraits (Babyak, Snyder, \& Yoshinoba, 1993). Thus, researchers often use AHS total score as a unitary measure of hope (e.g., Snyder et al., 1991). In the present study, we tested the hypothesis that a two-factor model that distinguishes between correlated dimensions of Agency and Pathways explains responses to the AHS better than does a one-factor model, we examined the strength of the relationship between agency and pathways, and we assessed the discriminant validity of agency and pathways in predicting coping and self-efficacy.

Another influential perspective on the construct of hope is the theoretical framework of Dufault and Martocchio (1985), as developed by Herth (1991) in the field of nursing research. Within this theoretical model, hope is conceptualized as "a multidimensional dynamic life force characterized by a confident yet uncertain expectation of achieving a future good which is realistically possible and personally significant" (Dufault \& Martocchio, 1985, p.380). Hope consists of two spheres-generalized hope, "an intangible umbrella that protects hoping persons by casting a positive glow on life" (Dufault \& Martocchio, 1985, p.380), and particularized hope, which concerns a specific outcome or hope object-which include affective, behavioral, cognitive, affiliative, temporal, and contextual components.

To operationalize the constructs in Dufault and Martocchio's (1985) model, Herth (1991) developed the Herth Hope Scale (HHS), consisting of 30 statements designed to tap three factors: Temporality and Future (the perceived likelihood of attaining the desired outcome), Positive Readiness and Expectancy (feelings of confidence), and Interconnectedness (the awareness of interdependence between self and others). Respondents use a 4 -point scale ( $1=$ strongly disagree, $4=$ strongly agree) to indicate their extent of agreement with each statement. Despite the underlying multidimensional model, researchers often treat the HHS as measuring a single global construct.

The present study examined the psychometric structure and discriminant validity of the HHS as a measure of dispositional hope. In particular, we sought to test the hypothesis that the factor reflecting Temporality and Future would relate most strongly to measures of opti- 
mism, whereas the factor reflecting feelings of self-confidence would relate more strongly to generalized self-efficacy. Although there are other notable models of hope, including those of Hinds (1984), Nowotny (1989), Post-White et al. (1996), and Staats and Stassen (1985), the conceptual models underlying Snyder et al.'s (1991) and Herth's (1991) instruments arguably have accumulated the most evidence supporting their construct validity.

\section{DISTINGUISHING OPTIMISM AND HOPE}

Comparing optimism and hope serves to highlight key points of theoretical divergence between the two constructs. These sources of conceptual distinctiveness can provide potentially useful insights into the trajectory of goal-directed behavior, persistence in the face of adversity, and the processes underlying adjustment to positive and negative life changes. A better understanding of the conceptual similarities and dissimilarities between hope and optimism would also help to improve conceptual clarity in the field of positive psychology.

Previous researchers have often blurred conceptual distinctions between optimism and hope. Although separate lines of theory and research have evolved for each construct, the two terms have frequently been used interchangeably in the literature, with optimists sometimes considered to be "hopeful" toward the future (e.g., Affleck \& Tennen, 1996) and pessimists said to exhibit "hopelessness" (e.g., Beck, Weissman, Lester, \& Trexler, 1974). Yet it remains unclear whether this mutual substitution of terms reflects their inherent conceptual equivalence or represents a lack of conceptual precision.

Although prior investigators have studied the relationship between optimism and hope, they have not directly tested competing measurement models for these two concepts in combination. Using exploratory factor analysis, for example, Magaletta and Oliver (1999) found a factor solution that distinguished optimism, hope, and self-efficacy, and they reported that these concepts "were all positively, significantly, and moderately intercorrelated" (p. 544). However, they did not systematically compare the goodness-of-fit of alternative factor models that combine optimism and hope.

Other researchers, in contrast, have used optimism and hope as dual indicators of a single global dimension reflecting future orientation. For example, Carvajal, Clair, Nash, and Evans (1998) used three separate measures as multiple indicators of a latent construct they termed "global expectancies of the self": optimism as assessed by the LOT, hope as assessed by the Children's Hope Scale (Snyder et al., 1997), and self-esteem as assessed by the Rosenberg Self-Esteem Scale (Rosenberg, 1965). They 
reported a correlation of 48 ( $23 \%$ shared variance) between measures of optimism and hope in a sample of 1,643 adolescents. Although Carvajal et al. (1998) modeled optimism and hope as both separate factors and one global personality construct, they reported results only for the latter model because of their broader interest in predicting substance use. The present study, in contrast, directly compared the validity and utility of each of these structural approaches to modeling optimism and hope.

When considered together, are optimism and hope more accurately conceptualized as one basic trait, or as two separate traits? We addressed this crucial question by testing three sets of hypotheses concerning: (a) the structure of hope and optimism measures analyzed together; (b) the strength of relationships between dimensions of hope and dimensions of optimism; and (c) divergent patterns of association between dimensions of hope and optimism in predicting key criterion variables.

The Structure of Hope and Optimism Combined. To assess conceptual distinctiveness, we compared alternative measurement models for the hope and optimism data analyzed together. Here we used higher-order measurement modeling to estimate the relationship between optimism and hope, in order to determine their degree of conceptual overlap versus uniqueness. If hope and optimism are truly distinct constructs, then a measurement model that distinguishes the two traits should fit the combined data better than a model that assumes the two traits reflect the same underlying construct. Based on the notion that hope and optimism are related forms of future orientation (Snyder et al., 2001), we expected hope and optimism to be moderately to strongly correlated, but not so highly interrelated as to be indistinguishable.

Tests of Discriminant Validity. We evaluated the discriminant validity of hope and optimism in two separate sets of analyses. In the initial set, we examined points of conceptual convergence and divergence between hope and optimism. Here we tested two alternative conceptualizations of the relationship between hope and optimism in the form of competing hypotheses: (a) that optimism relates more strongly to the agency dimension than to the pathways dimension of hope, consistent with the notion that the optimism model rests upon agency-like expectancies regarding goal attainment (Snyder et al., 2001); and (b) that optimism relates more strongly to the pathways dimension than to the agency dimension of hope (Snyder, 1991), based on the idea that faith in a positive future leads to greater persistence in seeking possible pathways to goal attainment, and to more "pathway thinking" (cf. Snyder, in press). Although these competing hypotheses come from the same theoretical perspective, a decade of research on hope has led to the general consensus that optimism has more to do with hope agency than with hope pathways (see Snyder et al., 2001). 
In the second set of analyses, we tested discriminant validity hypotheses about differences between the two hope factors and between the two optimism factors in predicting criterion measures.

These discriminant validity analyses were designed to clarify points of conceptual divergence between hope and optimism. With respect to optimism, the fact that the original LOT includes items reflecting the tendency to reappraise undesirable outcomes in a positive light underscores the presumed connection between generalized outcome expectancies and positive reinterpretation as a coping style. Along these lines, there is evidence that higher levels of optimism are associated with positive reappraisal as a means of coping with stress (Carver, Scheier, \& Weintraub, 1989; Curbow, Somerfield, Baker, Wingard, \& Legro, 1993; Davis, Nolen-Hoeksema, \& Larson, 1999; Fontaine, Mastead, \& Wagner, 1993). Indeed, Affleck and Tennen (1996) have suggested that optimists' "hopeful view of the future may well stem from a positive reinterpretation of the present" (p. 908). Based on the idea that optimists "see the glass as half full," we hypothesized that optimism would show a stronger relationship with positive reappraisal coping than would hope. In addition, we reasoned that the tendency to endorse positively-framed Optimism would relate more strongly to positive reappraisal than would the tendency to reject negatively-framed Pessimism.

On the other hand, the conception of hope as the combination of efficacy-based agency and goal-specific pathways sharply contrasts with the conception of optimism as a global, generalized outcome expectancy. Whereas hope's agency component necessarily implies a sense of personal responsibility for goal attainment, optimism implies no such personal attribution: "A person may hold favorable expectancies for a number of reasons-personal ability, because the person is lucky, or because he is favored by others. The result in any case should be an optimistic outlook-expectations that good things will happen" (Scheier \& Carver, 1985 , p. 223). This key conceptual difference suggests that by virtue of its agency subtrait, hope should be more closely linked than optimism to general self-efficacy. This reasoning also suggests a final discriminant validity hypothesis-namely, that the Agency factor will relate more strongly to general self-efficacy than will the Pathways factor.

\section{METHOD}

\section{PARTICIPANTS AND PROCEDURE}

The sample consisted of 351 undergraduates ( 265 females, 85 males, and one who did not indicate gender) from two metropolitan universities—one public $(n=35)$, one private $(n=316)$ —who participated either 
in return for psychology course credit or voluntarily without compensation. The disproportionate ratio of females to males reflects the gender compositions of the courses in which these students were enrolled. Mean age was 19.78 years $(S D=3.34)$. The sample was primarily Caucasian $(70 \%)$, with smaller numbers of Asian $(13 \%)$, Hispanic $(7 \%)$, and African-American ( $4 \%)$ participants. Either individually $(21 \%, n=75)$ or in groups of 5-10 $(79 \%, n=276)$, participants anonymously completed a battery of self-report questionnaires containing the main dependent measures. The order of questionnaires varied randomly across individuals. Exact sample size varied slightly across analyses due to missing data for some respondents.

\section{MEASURES}

Dispositional Optimism. We used the 12-item Life Orientation Test (LOT; Scheier \& Carver, 1985) to assess dispositional optimism. Respondents indicated their extent of agreement with each LOT item using a 5 -point scale ( 0 = strongly disagree, $1=$ disagree, $2=$ neutral; $3=$ agree; 4 $=$ strongly agree). As noted earlier, a great deal of converging evidence supports the reliability and validity of the LOT as a measure of dispositional optimism (see Chang, 2001; Gillham, 2000). Although we used the original LOT in studying the structure of optimism and its relations to hope, evidence indicates that LOT scores are highly correlated with scores on the revised LOT-R (Scheier et al, 1994). When analyzing the relationship of optimism to positive reappraisal, however, we omitted the LOT items that Scheier et al. (1994) eliminated in creating the LOT-R, to avoid inflating observed correlations. ${ }^{1}$

Hope. We used two different instruments to assess dispositional hope. The first of these was the 12-item Adult Hope Scale (AHS; Snyder et al.,

1. We had originally intended to administer the items from both the original LOT and the LOT-R for comparative purposes. However, we inadvertently omitted the additional optimism item that Scheier et al. (1994) added to the LOT-R (i.e., "Overall, I expect more good things to happen to me than bad"). Because of this clerical oversight, our revised Optimism subscale consisted of only two of the three positively-framed LOT-R items. Previous researchers (e.g., Affleck \& Tennen, 1996) have also used this two-item LOT-R Optimism subscale, in lieu of the three-item version. To examine the comparability of the two versions of the LOT-R Optimism subscale, we administered the full LOT-R to a comparable sample of 33 undergraduates ( 25 females, eight males; mean age $=19.85, S D=$ 1.03), and then correlated the two- and three-item versions of the Optimism subscale. This correlation was .96, $p<.00001$, indicating that the two versions of the revised Optimism subscale share $92 \%$ of their variance. Although this evidence does not prove that the two versions of the revised Optimism subscale are equivalent, it suggests that omitting the one LOT-R item does not alter the meaning of the Optimism subscale. 
1991). Respondents indicated their extent of agreement with each AHS item using an 8-point scale ( 1 = definitely false, $8=$ definitely true). As noted earlier, a large body of evidence supports the reliability and validity of the AHS as a measure of dispositional hope (see Snyder, in press; Snyder et al., 2001).

The second measure of hope that we used was the 30-item Herth Hope Scale (HHS; Herth, 1991). Respondents indicated their degree of agreement with each HHS item using a 4-point scale ( 1 = strongly disagree, $4=$ strongly agree). Herth (1991) reported that HHS total score has a Cronbach's $\alpha$ of .94, a two-week test-retest reliability of .91 , and discriminant validity in relation to a measure of pessimism, i.e., Beck et al.'s (1974) Hopelessness Scale.

Coping Style. We used the 60-item Coping Orientations to Problems Experienced scale (COPE; Carver, Scheier, \& Weintraub, 1989) to assess dispositional coping style. Respondents were asked to "indicate what you generally do and feel when you experience stressful events" using a 4-point scale (1 = I usually don't do this at all, 4 = I usually do this a lot). Although the COPE consists of 15 subscales, we analyzed only the 4-item Positive Reinterpretation subscale, which taps the degree to which respondents typically reframe the stressor in a positive light. An example of an item from this Positive Reinterpretation subscale is the following: "I try to see it in a different light, to make it seem more positive." Carver et al. (1989) reported a Cronbach's $\alpha$ for the Positive Reinterpretation subscale of .68, with an 8-week test-retest reliability of .48.

Self-efficacy. We used the 30-item Self-Efficacy Scale (SES; Sherer et al., 1982) to assess generalized sense of self-efficacy. The SES is intended to measure generalized expectations of personal mastery and success "dependent on past experiences and on tendencies to attribute success to skill as opposed to chance" (Sherer et al., 1982, p. 671). Respondents indicated their degree of agreement with SES items using a 5-point scale $(1=$ disagree strongly, 5 = agree strongly). SES items focus on dispositional willingness to initiate behavior, willingness to expend effort in completing the behavior, and persistence in the face of adversity. Although this instrument contains both general and social subscales, for present purposes we used only the former. An example of an item from the SES is the following: "When I make plans, I am certain I can make them work." Following Sherer et al.'s (1982) recommendations, we computed three composite indicators of general self-efficacy for use in our analyses: (a) the mean of SES items 2, 4, 15, 16, 23, and 27; (b) the mean of reverse-scored SES items 3, 7, 8, 11, and 12; and (c) the mean of reverse-scored SES items $18,20,22,26,29$, and 30. Sherer et al. (1982) reported a Cronbach's $\alpha$ of .86 for the full, 17-item general self-efficacy subscale. 


\section{ANALYTIC STRATEGY}

The analyses addressed four questions. (1) What is the most appropriate measurement model for each construct? To address this question, we used confirmatory factor analysis (CFA) to compare the goodness-of-fit of alternative measurement models for the hope and optimism data separately. (2) How closely related are hope and optimism? To address this question, we used CFA to evaluate the goodness-of-fit of alternative measurement models for the hope and optimism data analyzed together. (3) If the two traits are multidimensional, then are they more alike in some respects than in others? To address this question, we used CFA to compare the strength of the relationships among dimensions of hope and optimism. (4) Is optimism more strongly related to positive reappraisal coping, whereas hope is more strongly related to general self-efficacy? To address this question, we used structural equation modeling to test a priori hypotheses about divergent patterns of association (i.e., discriminant validity) between measures of hope and optimism and criterion measures of coping style and self-efficacy.

We used LISREL 8 (Joreskog \& Sorbom, 1996) to estimate CFA measurement models and to assess these models' goodness-of-fit to the data. CFA enabled us to evaluate and compare alternative models for hope and optimism, when considering each individually and both together. Structural equation modeling provided a means of systematically testing hypotheses about the structure of hope and of optimism, about the strength of their interrelationship, about the higher-order structure overarching hope and optimism, and about how hope and optimism differentially predict coping and self-efficacy.

When estimating measurement models, we used four criteria to assess a model's goodness-of-fit to the data (cf. Hu \& Bentler, 1998). Two of these criteria represent measures of absolute model fit: the root mean square error of approximation (RMSEA; Steiger, 1990) and the goodness-of-fit index (GFI; Joreskog \& Sorbom, 1996); and two represent measures of relative model fit: the comparative fit index (CFI; Bentler, 1990) and the nonnormed fit index (NNFI; Tucker \& Lewis, 1973). RMSEA reflects the size of the residuals that result when using the model to predict the data, adjusting for model complexity, with smaller values indicating better fit. According to Browne and Cudeck (1993), RMSEA <.05 represents "close fit"; RMSEA between .05 and .08 represents "reasonably close fit"; and RMSEA > 10 represents "an unacceptable model." Analogous to $R^{2}$ in multiple regression, GFI reflects the proportion of available variance-covariance information in the data that the given model explains, with larger GFI values representing better

model fit. CFI and NNFI, in contrast, both indicate how much better the 
given model fits the data relative to a "null" model, which assumes sampling error alone explains the covariation among observed measures (i.e., that there is no common variance among measured variables). Bentler and Bonett (1980) have suggested that measurement models have a GFI, CFI, and NNFI of at least .90.

\section{RESULTS AND DISCUSSION}

\section{OVERVIEW}

The analysis unfolded in three stages. In Stage 1, we assessed the fit of competing measurement models separately for optimism and for hope, in order to determine the most appropriate model for each construct. In Stage 2, we assessed the fit of competing measurement models for the combined hope and optimism data, in order to determine the degree of conceptual overlap versus uniqueness between hope and optimism. In Stage 3, we assessed the discriminant validity of dimensions of hope and optimism in predicting positive reappraisal coping and level of general self-efficacy.

\section{STAGE 1: DETERMINING THE STRUCTURE OF OPTIMISM AND HOPE WHEN ANALYZED SEPARATELY}

Optimism. We imposed two competing measurement models on the LOT data: (a) a one-factor model that assumes dispositional optimism is unidimensional (Scheier \& Carver, 1985), and (b) a two-factor model that assumes dispositional optimism consists of two correlated dimensions, positively-framed Optimism and negatively-framed Pessimism (Dember et al., 1989). Whereas the one-factor model provided a mediocre goodness-of-fit to the LOT data, $\chi^{2}(20, n=349)=162.2$, RMSEA $=$ $.164, \mathrm{GFI}=.87, \mathrm{CFI}=.83, \mathrm{NNFI}=.76$, the two-factor model fit the data well, $\chi^{2}(19, n=349)=33.2$, RMSEA $=.046, \mathrm{GFI}=.98, \mathrm{CFI}=.98, \mathrm{NNFI}=$ .98 , and was a significant improvement in fit over the one-factor model, $\Delta \chi^{2}(1, n=349)=129.0, p=<.00001$. These results support the conclusions of Dember et al. (1989), and suggest that dispositional optimism reflects two, negatively correlated dimensions (standardized $\phi=-.63, p=$ $<.00001$ ) that share about $40 \%$ of their variance.

Hope. Turning next to the two Hope instruments, we first considered the factor structure of Snyder et al.'s Adult Hope Scale (AHS). We evaluated two competing measurement models for the AHS data: (a) a one-factor model that assumes dispositional hope is unidimensional, and (b) a two-factor model that assumes dispositional hope consists of two correlated dimensions reflecting Agency and Pathways (Snyder et 
al., 1991). Whereas the one-factor model provided a mediocre goodness-of-fit to the AHS data, $\chi^{2}(20, n=349)=163.5$, RMSEA $=.162$, GFI $=$ $.87, \mathrm{CFI}=.84, \mathrm{NNFI}=.77$, the two-factor model fit the data well, $\chi^{2}(19, n=$ $349)=65.8, \mathrm{RMSEA}=.086, \mathrm{GFI}=.95, \mathrm{CFI}=.95, \mathrm{NNFI}=.92$, and was a significant improvement in fit over the one-factor model, $\Delta \chi^{2}(1, n=349)=$ 97.7, $p=<.00001$. These results support Snyder et al.'s (1991) bidimensional model, and suggest that Pathways and Agency share roughly half $(46 \%)$ of their variance (standardized $\phi=.68, p=<.00001$ ).

Two additional points are noteworthy regarding this two-factor model of hope. First, it is an equivalent model to Babyak et al.'s (1993) second-order CFA model of the AHS, which consists of two first-order factors with loadings constrained to be equal on a single, global second-order factor in order to identify the model (i.e., it generates an identical implied covariance matrix, and identical parameter indices and goodness-of-fit indices). Second, unlike Babyak et al. (1993), we find it unnecessary to add correlated error terms to the model in order to achieve acceptable fit.

We next examined the factor structure of the Herth Hope Scale (HHS). We tested two alternative models for the HHS data: (a) a one-factor model that assumes dispositional hope is unidimensional, and (b) a three-factor model that assumes dispositional hope consists of three correlated dimensions reflecting Temporality and Future, Positive Readiness and Expectancy, and Interconnectedness (Herth, 1991). Both the one-factor model, $\chi^{2}(405, n=344)=1794.4$, RMSEA $=.117$, GFI $=.69$, CFI $=.61, \mathrm{NNFI}=.58$, and the three-factor model, $\chi^{2}(402, n=344)=1738.8$, $\mathrm{RMSEA}=.114, \mathrm{GFI}=.70, \mathrm{CFI}=.62, \mathrm{NNFI}=.59$, provided a poor fit to the HHS data. Although the three-factor model fits the data better than the one-factor model, $\Delta \chi^{2}(3, n=344)=55.6, p<.00001$, both models remain inadequate. These results fail to confirm both the unidimensional "total score" model and the tripartite conceptual structure intended to underlie the Herth Hope Scale, and they suggest that further work is needed to develop an acceptable measurement model for the HHS. Because this was not a goal of the present research, however, we chose not to analyze the HHS data further, and instead used the AHS as our sole measure of dispositional hope.

Before abandoning the three-factor model for the Herth Hope Scale, we examined whether the model's poor fit was a function of the large number of observed variables in the measurement model. As Bagozzi and Heatherton (1994) have noted, measurement models containing more than about four to six indicators per factor are unlikely to fit the data satisfactorily. This is because including a larger set of unreliable measured variables in the measurement model, as opposed to a smaller subset of more reliable indicators, contributes more measurement error 
to the overall model, thereby reducing the proportion of explained variance and lowering measures of absolute model fit. For this reason, we considered the possibility that having ten measured indicators for each of Herth's (1991) three factors might predispose the three-factor model to fit poorly.

Accordingly, we reconfigured Herth's model into a "partially disaggregated" form that preserved the full range of "totally disaggregated" item content, while reducing the number of indicators per factor (cf. Bagozzi \& Edwards, 1998; Bagozzi \& Heatherton, 1994). To do this, we converted the ten single-item indicators for each HHS factor into three composite measures or "item parcels," using as indicators the mean of the first three items, the mean of the second three items, and the mean of the last four items. As with the totally disaggregated data, both the one-factor model, $\chi^{2}(27, n=344)=198.1$, RMSEA $=.150$, GFI = $.87, \mathrm{CFI}=.82, \mathrm{NNFI}=.76$, and the three-factor model, $\chi^{2}(24, n=344)=$ $191.6, \mathrm{RMSEA}=.159, \mathrm{GFI}=.87, \mathrm{CFI}=.82, \mathrm{NNFI}=.73$, provided an unsatisfactory fit to the partially disaggregated HHS data. Thus, even in a "partially disaggregated" form, our HHS data do not support Herth's (1991) unidimensional or multidimensional measurement models.

\section{STAGE 2: DETERMINING THE STRUCTURE OF OPTIMISM AND HOPE WHEN ANALYZED TOGETHER}

Having confirmed the bidimensionality of optimism and of hope, we next considered the question of whether hope and optimism are two separate constructs, or manifestations of the same global underlying trait. To answer this question, we evaluated the goodness-of-fit of four alternative measurement models for the LOT (eight items) and AHS (eight items) data when analyzed together: (a) a one-factor model that assumes all 16 items reflect a single, global dimension termed Future Orientation; (b) a four-factor model that assumes four correlated dimensions (Optimism, Pessimism, Agency, and Pathways) underlie responses to the 16 items; (c) a higher-order model in which a single second-order factor (Future Orientation) underlies the covariation among four first-order factors (Optimism, Pessimism, Agency, and Pathways); and (d) a higher-order model consisting of two, correlated second-order factors (Optimism and Hope), the first of which underlies the covariation between the first-order factors of Optimism and Pessimism, and the second of which underlies the covariation between the first-order factors of Agency and Pathways.

First-order CFA Models. As expected, the one-factor model provided a poor fit to the combined LOT and AHS data, $\chi^{2}(104, n=341)=629.2$, $\mathrm{RMSEA}=.140, \mathrm{GFI}=.77, \mathrm{CFI}=.72, \mathrm{NNFI}=.68$, whereas the four-factor 
TABLE 1. Reliabilities and Intercorrelations for Dimensions of Optimism (Optimism and Pessimism) and Hope (Pathways and Agency)

\begin{tabular}{lrrrr}
\hline & Optimism & Pessimism & Pathways & Agency \\
\hline Optimism & .76 & & & \\
Pessimism & -.63 & .80 & & \\
Pathways & .52 & -.45 & .76 & .80 \\
Agency & .54 & -.60 & .68 & .80 \\
\hline
\end{tabular}

Note. $N=341$. Tabled on the diagonal are Cronbach's alphas (i.e., reliability coefficients of internal consistency) for unit-weighted factor scores for each subscale. Tabled below the diagonal are standardized $\phi$ coefficients (analogous to Pearson correlation coefficients) from a four-factor confirmatory factor analysis. These coefficients reflect the degree of association between latent constructs that have been adjusted for differences in measurement reliability. All $\phi$ s are statistically significant at $p<.00001$.

model fit the combined LOT and AHS data well, $\chi^{2}(98, n=341)=191.9$, $\mathrm{RMSEA}=.053, \mathrm{GFI}=.94, \mathrm{CFI}=.95, \mathrm{NNFI}=.94$. Table 1 presents the correlations (i.e., standardized $\phi s$ ) among the two optimism factors (Optimism and Pessimism) and the two hope factors (Agency and Pathways). Note that the factors tend to be more strongly correlated within each instrument than they are across instruments. Whereas the two Optimism factors share $40 \%$ of their variance and the two Hope factors share nearly half $(47 \%)$ of their variance, dimensions of hope and optimism have only one-fifth (Pathways and Pessimism) to one-third (Agency and Pessimism) of their variance in common. Contrary to our hypotheses, the Optimism factor correlated equally with both Agency $(\phi=.52)$ and Pathways $(\phi=.54), \Delta \chi^{2}(1, n=341)=0.2, p>.65$. However, Pessimism correlated more strongly with Agency $(\phi=-.60)$ than with Pathways $(\phi=$ $-.45), \Delta \chi^{2}(1, n=341)=6.2, p<.013$. These results support the discriminant validity of the optimism and hope factors, and they suggest that optimism and hope have most in common their respective components of pessimism and agency.

Higher-order CFA Models. We next evaluated the goodness-of-fit of two higher-order measurement models for the hope and optimism data analyzed together. The first higher-order model consists of a single second-order factor (Future Orientation) influencing all four first-order factors. This hierarchical CFA model provided a reasonable fit to the combined LOT and AHS data, $\chi^{2}(100, n=341)=210.2$, RMSEA $=.057$, GFI $=$ $.93, \mathrm{CFI}=.94, \mathrm{NNFI}=.93$. We next examined the goodness-of-fit of an alternative higher-order model consisting of two, correlated second-order factors-Hope influencing the two first-order AHS factors, and Optimism influencing the two first-order LOT factors. This second hierarchical CFA model also provided an acceptable fit to the combined LOT and 
AHS data, $\chi^{2}(99, n=341)=195.4$, RMSEA $=.054$, GFI $=.93$, CFI $=.95$, NNFI $=.94$. Supporting the notion that hope and optimism represent two separate constructs, the model with separate second-order factors of Optimism and Hope provided a better fit to the LOT and AHS data analyzed together than did the higher-order model with a single second-order factor, $\Delta \chi^{2}(1, n=341)=14.8, p<.00012$.

How strongly related are hope and optimism? The correlation (standardized $\phi$ ) between the two second-order factors in the higher-order model was .80, $p<.00001$, indicating that hope and optimism share roughly two-thirds $(64 \%)$ of their variance. Thus, when controlling for measurement error, the two concepts have about twice as much in common as they have separate from each other. The Pearson correlation between unit-weighted total scores for the AHS and the LOT was .54 ( $p$ $<.00001$ ), representing $29 \%$ shared variance. Clearly, unreliability in the AHS and LOT attenuates the apparent strength of the relationship between hope and optimism.

How should we interpret these results? Is it more appropriate to conceive of hope and optimism as distinct but related concepts, or is their interrelationship too strong to justify separate constructs? On the one hand, conceptualizing hope and optimism as reflections of the same higher-order model is parsimonious, as the two concepts do share a sizeable portion of their variance. Indeed, imposing a single, second-order latent variable on the two first-order AHS factors and two first-order LOT factors provided a reasonable goodness-of-fit to the combined hope and optimism data. On the other hand, compared to assuming only a single second-order factor, positing two separate second-order factors of Hope and Optimism fits the data better and explains a greater proportion of variance in the first-order Optimism (.62 vs. .53), Pessimism (.64 vs. .54), Agency (.80 vs. .68), and Pathways (.58 vs. .55) factors. This conceptual quandary makes it all the more crucial to assess the discriminant validity of hope and optimism (which we address in Stage 3 of the analyses).

The hierarchical model with two second-order factors also enables us to determine the degree to which the first-order factors equally define their respective overarching second-order constructs of hope and optimism. Imposing equality constraints on the absolute value of second-order factor loadings reveals that: (a) Optimism (completely standardized $\gamma=.79)$ and Pessimism $(\gamma=-.80)$ were equally indicative of dispositional optimism, $\Delta \chi^{2}(1, n=341)=1.5, p>.22$, and (b) Agency $(\gamma=.76)$ and Pathways $(\gamma=.89)$ were equally indicative of dispositional hope, $\Delta \chi^{2}(1, n=$ $341)=2.8, p>.09$. Of additional interest in this higher-order measurement model is the unexplained residual variance in each first-order factor, after removing the variance it shares with the overarching sec- 
ond-order construct. Imposing equality constraints on residual variance estimates for first-order factors revealed that the first-order Optimism and Pessimism factors had equal amounts of specific variance, $\Delta \chi^{2}(1, n=$ $341)=0.4, p>.34$, as did the first-order Agency and Pathways factors, $\Delta \chi^{2}(1, n=341)=1.3, p>.09$.

\section{STAGE 3: ASSESSING THE DISCRIMINANT VALIDITY OF OPTIMISM AND HOPE}

In the final stage of the analysis, we used LISREL 8 to test hypotheses about the pattern of relationships between (a) the personality measures of hope and optimism and (b) the criterion measures of coping and self-efficacy. We used structural equation modeling rather than multiple regression because it allowed us to estimate the relationships between personality traits and criterion variables, partialling out measurement error in the measured indicators. It also enabled us to use equality constraints to test hypotheses about the strength of the relationships among latent variables.

To assess discriminant validity, we imposed two different latent-variable path models on the combined data set, each of which used the hope and optimism measures to predict the criterion measures. The first was a hierarchical path model consisting of two, correlated second-order factors (Hope as defined by the two first-order AHS factors, and Optimism as defined by the two first-order LOT factors), each influencing the endogenous latent variables of Positive Reappraisal and General Self-Efficacy. This hierarchical path model allowed us to examine the discriminant validity of the second-order factors of Hope and Optimism as predictors of coping and self-efficacy. The second latent-variable path model consisted of four correlated, exogenous latent variables (Optimism, Pessimism, Agency, and Pathways), each influencing the endogenous latent variables of Positive Reappraisal and General Self-Efficacy. The path model with four exogenous latent variables allowed us to test discriminant validity within each pair of factors in the bidimensional models of Hope and Optimism. In both of these structural models, we omitted from the model the LOT items that Scheier et al. (1994) dropped in their revised version of the LOT, so as to avoid inflating the apparent relationship between optimism and positive reappraisal coping. (Results using the original LOT items were comparable, though of slightly lower magnitude.)

Having an excessive number of estimated parameters in structural models reduces statistical power, making it more difficult to detect existing relationships, and weakening apparent model fit. To reduce the number of estimated parameters in our structural models, we adopted a 
"partial disaggregation" measurement model (Bagozzi \& Edwards, 1998; Bagozzi \& Heatherton, 1994), in which we minimized the number of measured variables by parceling them into two indicators for each latent variable. The primary advantages of the "partial disaggregation" (molecular) approach, relative to a "total disaggregation" individual item (atomistic) approach, are: (a) it reduces the number of parameters to be estimated, so that smaller sample sizes are required; and (b) it tends to decrease measurement errors in indicators by aggregating items to form more reliable, composite indices, so that models generally fit the data better (Bagozzi \& Edwards, 1998; Bagozzi \& Heatherton, 1994). Comparing their totally and partially disaggregated forms, the hierarchical path model had 55 versus 33 estimated parameters (a $40 \%$ reduction), and the path model with four exogenous latent variables had 56 estimated parameters versus 38 (a 32\% reduction). These reductions kept sample size close to the recommended ratio of 10:1, relative to the number of estimated model parameters (Kline, 1998).

In these partial disaggregation measurement models, the pairs of indicators for each latent variable were as follows: (a) Optimism (LOT items 1 and 5); (b) Pessimism (the mean of LOT items 3 and 8; and LOT item 12); (c) Pathways (the mean of AHS items 1 and 4; and the mean of AHS items 6 and 8); (d) Agency (the mean of AHS items 2 and 9; and the mean of AHS items 10 and 12); (e) Positive Reappraisal (the mean of COPE items 1 and 29; and the mean of COPE items 38 and 59); and (f) General Self-Efficacy (the mean of SES items 2, 4, 15, 16, 23, 27 and of reverse-scored SES items 3, 7, 8, 11, 12; and the mean of reverse-scored SES items 18, 20, 22, 26, 29, and 30). Note that we excluded from our discriminant validity analyses the LOT items that Scheier et al. (1994) eliminated in creating the LOT-R, so as to avoid inflating the relationship between optimism and positive reappraisal.

Higher-order Model. The hierarchical path model provided an acceptable fit to the combined data from the LOT, the AHS, and the criterion measures, $\chi^{2}(45, n=347)=95.2$, RMSEA $=.058, \mathrm{GFI}=.96$, CFI $=.97$, NNFI $=.96$, and afforded a direct test of discriminant validity for the second-order Hope and Optimism factors. Figure 1 presents a structural diagram of this "partial disaggregation" hierarchical model, along with the completely standardized LISREL estimates of model parameters.

We used equality constraints to test two discriminant validity hypotheses about the strength of the relationships between the second-order factors of Hope and Optimism and the first-order criterion factors: (a) optimism is more strongly related to positive reappraisal coping than is hope; and (b) hope is more strongly related to general self-efficacy than is optimism. We tested each hypothesis separately by constraining the influence of the second-order factors on the given criterion measure to 

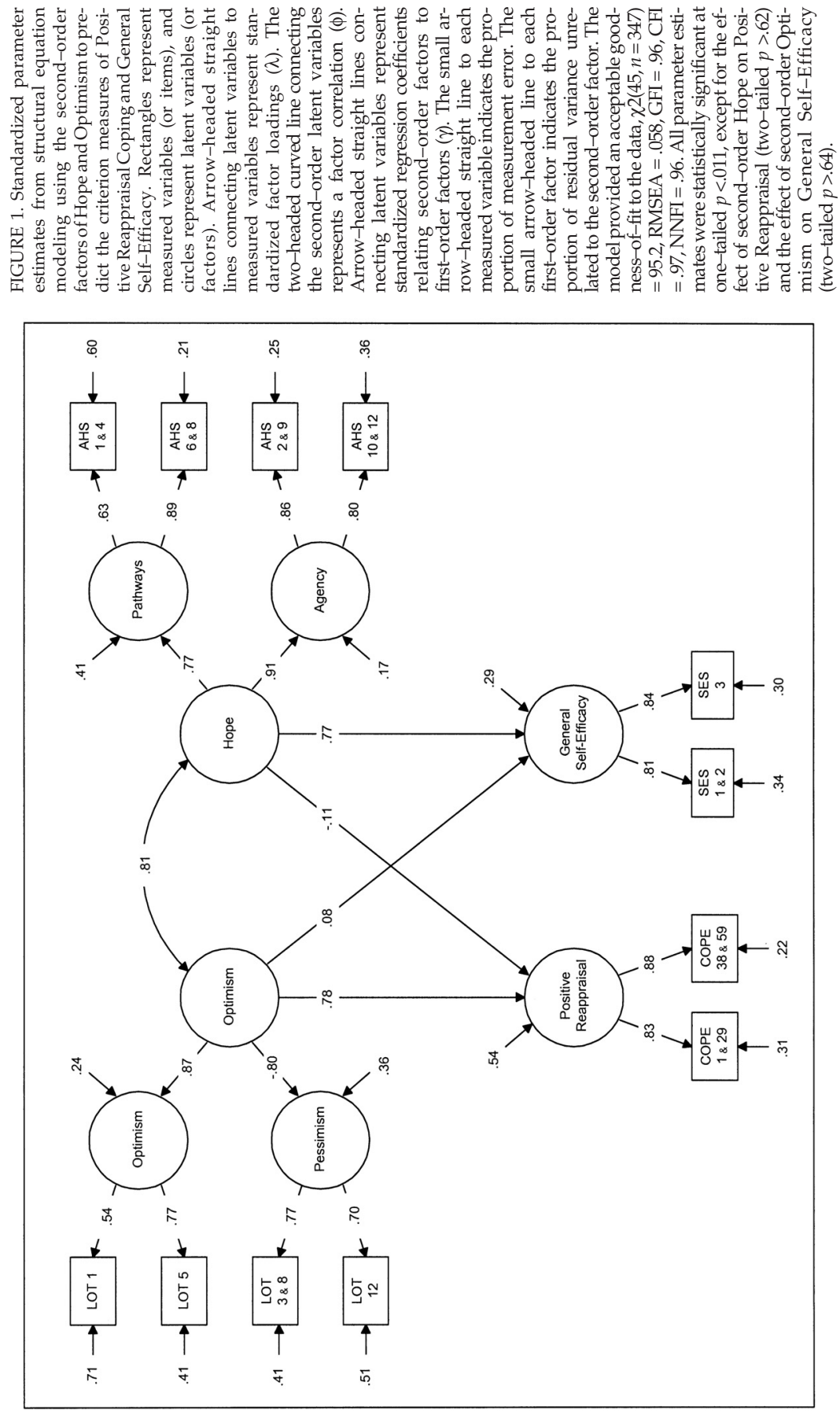
be equal, and then contrasting this nested model's goodness-of-fit with that of the baseline model containing no equality constraints. The difference in these two goodness-of-fit chi-square values provides a likelihood-ratio test of the hypothesis that the two second-order factors have different relationships with the given criterion factor (see Bryant, 2001; Bryant \& Baxter, 1997).

Confirming predictions, second-order Optimism had a stronger influence on the use of positive reappraisal as a coping strategy than did second-order Hope, $\Delta \chi^{2}(1, n=347)=4.4$, one-tailed $p<.018$, whereas second-order Hope had a stronger influence on level of general self-efficacy than did second-order Optimism, $\Delta \chi^{2}(1, n=347)=4.9$, one-tailed $p<.014$ (see Figure 1). Indeed, controlling for the influence of the other second-order trait, Optimism was a statistically significant predictor of positive reappraisal, standardized $\gamma=.78$, one-tailed $p<.0016$, whereas Hope was not, standardized $\gamma=-.11$, two-tailed $p>.62$; and Hope was a statistically significant predictor of general self-efficacy, standardized $\gamma$ $=.77$, one-tailed $p<.00004$, whereas Optimism was not, standardized $\gamma=$ .08 , two-tailed $p>.64$. These results support the discriminant validity of hope and optimism.

First-order Model. The latent-variable path model using the two first-order hope factors and the two first-order optimism factors to predict the two criterion factors also provided an acceptable goodness-of-fit to the data, $\chi^{2}(40, n=347)=81.2$, RMSEA $=.053$, GFI $=.96, \mathrm{CFI}=.98$, $\mathrm{NNFI}=.96$. This first-order model enabled us to test discriminant validity hypotheses about differences between the two hope factors and between the two optimism factors in predicting criterion measures. Table 2 presents the results for this structural model, in terms of the standardized regression coefficients using optimism, pessimism, pathways, and agency to predict coping and self-efficacy.

Initial tests of homogeneity in path coefficients (i.e., the absence of discriminant validity) revealed that the four hope and optimism factors had different relationships with Positive Reappraisal, $\Delta \chi^{2}(3, n=347)=$ $49.9, p<.00002$, and with General Self-Efficacy, $\Delta \chi^{2}(3, n=347)=112.7, p$ $<.00001$. Confirming our a priori hypotheses, within the Optimism domain, Optimism was a stronger predictor of Positive Reappraisal than was Pessimism, $\Delta \chi^{2}(1, n=347)=5.8$, one-tailed $p<.0082$; and within the Hope domain, Agency was a stronger predictor of General Self-Efficacy than was Pathways, $\Delta \chi^{2}(1, n=347)=7.8$, one-tailed $p<.0027$. Indeed, multiple regression analyses of mean subscale scores reveals that: (a) entering Agency and Pathways as a set of predictors after first entering Optimism and Pessimism significantly improves the variance explained in both Positive Reinterpretation, $\Delta R^{2}=.04, F(2,344)=9.3, p<.0002$, and General Self-Efficacy, $\Delta R^{2}=.18, F(2,344)=60.2, p<.00001$; and (b) enter- 
TABLE 2. Standardized Regression Coefficients from Latent Variable Path Model Using Dimensions of Optimism (Optimism and Pessimism) and Hope (Pathways and Agency) to Predict Criterion Measures

\begin{tabular}{lrrrrr}
\hline & \multicolumn{5}{c}{ Criterion Measures } \\
\cline { 2 - 3 } \cline { 5 - 6 } Dimensions of & $\gamma$ & $p<$ & $\gamma$ & $p<$ \\
\cline { 2 - 4 } Optimism and Hope & .57 & .0004 & .05 & .32 \\
\cline { 2 - 3 } Optimism & .02 & .96 & -.26 & .005 \\
Pessimism & .07 & .26 & .05 & .30 \\
Pathways & .10 & .18 & .56 & .0000 \\
Agency & .45 & & .67 & \\
$R^{2}$ & & & & & \\
\end{tabular}

Note. $N=347$. Tabled are completely standardized $\gamma$ (gamma) coefficients (analogous to standardized betas in multiple regression) from structural equation modeling. These coefficients reflect the degree of association between latent constructs that have been adjusted for differences in measurement reliability. All $p$-values are one-tailed, except for that associated with the path coefficient linking pessimism to positive reappraisal coping. Initial tests of homogeneity among path coefficients (i.e., the absence of discriminant validity) revealed that the four hope and optimism factors had different relationships with Positive Reappraisal, $\Delta \chi(3, n=339)=49.9, p<.00001$, and with General Self-Efficacy, $\Delta \chi^{2}(3, n=339)=112.7, p<.00001$. Cronbach's alphas (i.e., reliability coefficients of internal consistency) for unit-weighted factor scores on these subscales were: Optimism (.76), Pessimism (.80), Pathways (.76), and Agency (.80), Positive Reappraisal Coping (.78), and General Self-Efficacy (.80).

ing Optimism and Pessimism as a set of predictors after first entering Agency and Pathways significantly improves the variance explained in both Positive Reinterpretation, $\Delta R^{2}=.16, F(2,344)=43.3, p<.00001$, and General Self-Efficacy, $\Delta R^{2}=.05, F(2,344)=18.0, p<.00001$. These findings support the discriminant validity of the bidimensional models of optimism and hope.

\section{CONCLUSIONS}

The present study contributes to the literature on positive psychology by explicating the relationship between the central personality constructs of optimism and hope, by highlighting their points of conceptual overlap and divergence, and by demonstrating their discriminant validity in predicting coping and self-efficacy. With respect to dispositional optimism, our results strongly support a two-dimensional conceptualization that distinguishes between the rejection of pessimism and the endorsement of optimism as different forms of generalized future expectancy. The bidimensionality of optimism suggests that people may be neither optimistic nor pessimistic (e.g., having no generalized future 
expectancies), rather than necessarily being either an optimist or pessimist. As Albert Schweitzer observed, "An optimist is a person who sees a green light everywhere, while a pessimist sees only the red stoplight...The truly wise person is colorblind." However, the traditional unidimensional model of optimism - which has optimism at one end of the continuum and pessimism at the other-forces the "truly wise person" (who rejects both optimism and pessimism) to score at the midpoint on the single optimism-pessimism continuum. With the bidimensional model, in contrast, the "truly wise person" can have low scores on both the optimism and pessimism subscales. Indeed, $5 \%(n=$ 16) of our sample scored in the lowest quartile on both the optimism and pessimism subscales.

The bidimensionality of optimism also suggests that people may be both optimistic and pessimistic, as when an individual defensively expresses pessimism in public, but is privately optimistic (e.g., Norem \& Cantor, 1986). Whereas the unidimensional model forces the defensive pessimist to score at the midpoint on the single optimism-pessimism continuum, the two-factor model permits the defensive pessimist to have high scores on both the optimism and pessimism subscales. In fact, $9 \%(n=31)$ of our sample scored in the highest quartile on both the optimism and pessimism subscales.

Although optimism and pessimism overlap roughly $40 \%$, they are more accurately conceptualized as two separate traits, not as two ends of the same bipolar continuum. In particular, optimism is a stronger predictor of positive reinterpretation coping than is pessimism, whereas pessimism is a stronger predictor of general self-efficacy than is optimism. This evidence strongly supports the discriminant validity of the distinction between optimism and pessimism. Combining optimism and pessimism into a total score might obscure findings that would emerge for one dimension but not the other (Affleck \& Tennen, 1996). The distinction between being optimistic versus not being pessimistic is consistent with clinical findings concerning the differential effects of positive versus non-negative thinking on depressive symptomatology (Hollon \& Kendall, 1980).

By the same token, our results concerning hope also demonstrate unequivocally that having a generalized sense of agency in relation to the future is not the same as having a generalized notion of specific pathways to the future. The Will and the Ways represent correlated but separate aspects of goal-orientation. Indeed, Agency shows a stronger association with general self-efficacy than does Pathways. Hope is more accurately conceptualized as separate, positively correlated dimensions of Agency and Pathways, rather than as a unitary construct. Treating hope as unidimensional merges Agency and Pathways and might well 
produce erroneous conclusions about the antecedents and consequences of hope.

Our data also suggest that Snyder et al.'s (1991) AHS is a psychometrically superior measure of dispositional hope compared to Herth's (1991) HHS. We were unable to confirm the three-factor measurement model intended to underlie the HHS, nor was a one-factor "total score" model a reasonable representation of responses to the HHS. Clearly, further work is needed to refine the set of HHS items, in order to develop an acceptable measurement model for this instrument. Until then, researchers who wish to assess dispositional hope would do better to use the AHS rather than the HHS.

Should researchers conceive of hope and optimism as two separate constructs or as reflections of the same global underlying trait? Our data indicate that both conceptualizations have merit. Supporting two distinct constructs, separate second-order hope and optimism factors have greater explanatory power than does a single global "super" factor, and the two constructs show divergent patterns of association with coping and self-efficacy. Supporting a unitary conceptualization, on the other hand, second-order hope and optimism share a sizeable portion (64\%) of their variance, and a single global "super" factor provides a reasonable and parsimonious goodness-of-fit to the data. Perhaps both traits reflect a general third-order tendency toward constructive future-focused thinking (Epstein \& Meier, 1989). The ultimate choice between distinguishing or merging hope and optimism may well depend on whether the researcher seeks to maximize predictive accuracy or simply to summarize individuals' future orientation. Our results clearly indicate that investigators studying the effects of future expectancies on physical and emotional outcomes would do better to model hope and optimism as separate but related constructs; however, investigators who wish merely to assess global future orientation, in contrast, could adopt a unidimensional second-order model to gain a general summary, without losing too much information.

An important finding from this research is that hope has more to do with general self-efficacy than does optimism, whereas optimism has more to do with positive reappraisal coping than does hope. This differential pattern of relations would not have emerged, if hope and optimism were one in the same. We suggest that optimism has stronger implications for dispositional cognitive appraisals of personal outcomes, whereas hope is more strongly tied to dispositional beliefs about personal capabilities.

One potential conceptual problem concerns our choice of self-efficacy as a criterion measure for hope. These two constructs may well have a conceptual overlap similar to that of optimism and hope. Indeed, it 
could be argued that hope, optimism, and self-efficacy all tap a single overarching factor. If all three concepts are interchangeable, however, then a one-factor model should provide a reasonable goodness-of-fit when analyzing the optimism, hope, and self-efficacy data together; and the fit of this one-factor model should resemble that of a three-factor model that distinguishes separate, correlated factors of optimism, hope, and self-efficacy.

However, supplementary analyses of our data reveal that this is not the case. On the contrary, the one-factor model, $\chi^{2}(152, n=339)=817.82$, $\mathrm{RMSEA}=.129, \mathrm{GFI}=.76, \mathrm{CFI}=.74, \mathrm{TLC}=.70$, fit the combined data significantly worse than did the three-factor model, $\chi^{2}(149, n=339)=$ $540.70, \mathrm{RMSEA}=.099, \mathrm{GFI}=.83, \mathrm{CFI}=.84, \mathrm{TLC}=.82 ; \Delta \chi^{2}(3, n=339)=$ $277.12, p<.00001$. In addition, both two-factor models that we tested-Hope with a combined Optimism and Self-Efficacy factor, $\chi^{2}(151, n=339)=696.67, \mathrm{RMSEA}=.117, \mathrm{GFI}=.79, \mathrm{CFI}=.78, \mathrm{TLC}=.76$, and Optimism with a combined Hope and Self-Efficacy factor, $\chi^{2}(151, n$ $=339)=611.25, \mathrm{RMSEA}=.106, \mathrm{GFI}=.82, \mathrm{CFI}=.82, \mathrm{TLC}=.79$-fit the combined data significantly worse than did the three-factor model, $\Delta \chi^{2} \mathrm{~s}$ $(2, n=339)=155.97$ and 70.55, respectively, $p$ s <.00001. Considered together, these findings suggest that self-efficacy is better conceptualized as a separate, correlated construct in relation to hope and optimism, rather than as a conceptually overlapping construct (cf. Magaletta \& Oliver, 1999). This supports our use of general self-efficacy as a criterion measure for hope.

Nevertheless, there is another potential problem with our choice of general self-efficacy as a criterion for hope. Unlike the criterion for optimism-i.e., positive reappraisal-self-efficacy is not an index of behavior. It would have been more advantageous to select a criterion for hope that reflects behavior rather than belief, such as behavioral persistence or problem-solving efforts.

Our results also shed light on ways in which hope and optimism are similar and ways in which the two traits are different. The subtrait of dispositional pessimism is more distinct from hope when hope is defined as Pathways (20\% shared variance) than when hope is defined as Agency (36\% shared variance). This result is consistent with the notion that generalized pessimism rests upon agency-like expectancies regarding goal attainment (cf. Snyder et al., 2001). The strong connections often found among negative thoughts about the future, the self, and world (e.g., Beck, 1967; Bryant \& Baxter, 1997; Hollon \& Kendall, 1980) are consistent with the stronger conceptual overlap between Pessimism and Agency. That the Pathways subtrait is more distinct from Pessimism confirms the notion that it is possible to know the means through which 
one might attain one's goals, yet still doubt that one will ever achieve those goals.

This line of reasoning suggests that hope focuses more directly on expectations about the personal attainment of specific goals, whereas optimism focuses more broadly on the expected quality of future outcomes in general. Indeed, Affleck and Tennen (1996) have argued that hope is specifically "based on the perceived accessibility of desired goals" (p. 911). As Leon Tec aptly noted, "A sailor without a destination cannot hope for a favorable wind." A sailor without a destination has no goal, no hope object in relation to which to perceive agency and pathways. Extending this metaphor further, our data indicate that a sailor who has a destination but lacks commitment to the voyage (i.e., who lacks Agency) would be likely to be pessimistic about reaching that destination; whereas a committed sailor who has a destination but no ship (i.e., who lacks Pathways) might still refuse to be pessimistic about the ultimate likelihood of reaching that destination. Pessimism has more to do with lack of agency than with lack of pathways.

Several important limitations constrain our research conclusions. Concerning the issue of construct validity, our criterion measures were exclusively self-report and did not include behavioral or physiological indicators, such as task persistence or immunology. Concerning external validity issues, our sample was restricted exclusively to college undergraduates, $90 \%$ of whom attended a private university where more than half of students are Catholic. Hope and optimism might well be more distinct in older groups or among individuals of different religious backgrounds.

A final point concerns future directions for the conceptualization and measurement of hope and optimism. In explaining the partial independence of optimism and pessimism, Marshall et al. (1992) have suggested that the lack of correspondence between the two may "be due to whether people have proximal or distal goals in mind. A person might, for example, be pessimistic over the short run, but optimistic with respect to broader or more far-reaching outcomes" (p. 1072). This temporal perspective seems equally applicable to the concept of hope, which may have a different meaning in relation to shorter-term versus longer-term goals. For example, the Arabic language includes two terms for hope: "raja 'a," which is more formal and refers primarily to expectancies directed in relation to the distant future, and "amal," which is more infor$\mathrm{mal}$ and refers to expectancies in relation to the immediate and unfolding present (Abi-Hashem, 2001). Researchers might well gain deeper insights into the meaning of both hope and optimism by distinguishing short-term and long-term future expectancies. For example, having respondents complete the LOT and AHS twice, focusing once on proximal 
outcomes and once on distant outcomes, might reveal that responses to each instrument are more unidimensional within than across the two time frames.

\section{REFERENCES}

Abi-Hashem, N. (2001). Rediscovering hope in American psychology. American Psychologist, 56, 85-86.

Affleck, G., \& Tennen, H. (1996). Construing benefits from adversity: Adaptational significance and dispositional underpinnings. Journal of Personality, 64, 899-922.

Babyak, A.M., Snyder, C.R., \& Yoshinoba, L. (1993). Psychometric properties of the Hope Scale: A confirmatory factor analysis. Journal of Research in Personality, 27, 154-159.

Bagozzi, R. P., \& Edwards, J. R. (1998). A general approach for representing constructs in organizational research. Organizational Research Methods, 1, 45-87.

Bagozzi, R. P., \& Heatherton, T. F. (1994). A general approach to representing multifaceted personality constructs: Application to state self-esteem. Structural Equation Modeling, 1, 35-67.

Beck, A. T. (1967). Depression: Clinical, experimental, and theoretical aspects. New York: Harper \& Row.

Beck, A.T., Weissman, A., Lester, D., \& Trexler, L. (1974). The measurement of pessimism: A hopelessness scale. Journal of Consulting and Clinical Psychology, 42, 861-865.

Bentler, P.M. (1990). Comparative fit indexes in structural models. Psychological Bulletin, 107, 238-246.

Bentler, P.M., \& Bonett, D.G. (1980). Significance tests and goodness of fit in the analysis of covariance structures. Psychological Bulletin, 88, 588-606.

Browne, M.W., \& Cudeck, R. (1993). Alternative ways of assessing model fit. In K.A. Bollen \& J.S. Long (Eds.), Testing structural equation models (pp. 136-162). Newbury Park, CA: Sage.

Bryant, F.B. (2001). Assessing the validity of measurement. In L.G. Grimm \& P.R. Yarnold, (Eds.), Reading and understanding more multivariate statistics (pp. 99-146). Washington, DC: American Psychological Association.

Bryant, F.B., \& Baxter, W.J. (1997). The structure of positive and negative automatic cognition. Cognition and Emotion, 11, 225-258.

Bryant, F.B., \& Veroff, J. (1984). Dimensions of subjective mental health in American men and women. Journal of Health and Social Behavior, 25, 116-135.

Bryant, F.B., \& Yarnold, P.R. (1995). Principal-components analysis and exploratory and confirmatory factor analysis. In L.G. Grimm \& P.R. Yarnold (Eds.), Reading and understanding multivariate statistics (pp. 99-136). Washington, DC: American Psychological Association.

Carvajal, S.C., Clair, S.D., Nash, S.G., \& Evans, R.I. (1998). Relating optimism, hope, and self-esteem to social influences in deterring substance use in adolescents. Journal of Social and Clinical Psychology, 17, 443-465.

Carver, C. S., Scheier, M. F., \& Weintraub, J.K. (1989). Assessing coping strategies: A theoretically based approach. Journal of Personality and Social Psychology, 56,267-283.

Chang, E.C. (Ed.) (2001). Optimism and pessimism. Washington, DC: American Psychological Association.

Chang, E.C., D'Zurilla, T. J., \& Maydeu-Olivares, A. (1994). Assessing the dimensionality 
of optimism and pessimism using a multimeasure approach. Cognitive Therapy and Research, 18, $143-160$.

Colligan, R.C., Offord, K. P., Malinchoc, M., Schulman, P., \& Seligman, M.E.P. (1994). CAVEing the MMPI for an Optimism-Pessimism Scale: Seligman's attributional model and the assessment of explanatory style. Journal of Clinical Psychology, 50, 71-95.

Csikszentmihalyi, M. (1990). Flow: The psychology of optimal experience. New York: Harper \& Row.

Curbow, B., Somerfield, M., Baker, F., Wingard, J., \& Legro, M. (1993). Personal changes, dispositional optimism, and psychological adjustment to bone marrow transplantation. Journal of Behavioral Medicine, 16, 423-443.

Davis, C., Nolen-Hoeksema, S., \& Larson, J. (1999). Making sense of loss and benefiting from the experience: Two construals of meaning. Journal of Personality and Social Psychology, 75, 561-574.

Dember, W.N., Martin, S., Hummer, M.K., Howe, S., \& Melton, R. (1989). The measurement of optimism and pessimism. Current Psychology: Research and Reviews, 8, 102 -119 .

Diener, E. (1984). Subjective well-being. Psychological Bulletin, 95, 542-575.

Dufault, K. J. \& Martocchio, B. C. (1985). Hope: Its spheres and dimensions. Nursing Clinics of North America, 20, 379-391.

Epstein, S., \& Meier, P. (1989). Constructive thinking: A broad coping variable with specific components. Journal of Personality and Social Psychology, 57, 332-350.

Fischer, M., \& Leitenberg, H. (1986). Optimism and pessimism in school-aged children. Child Development, 57, 241-248.

Fontaine, K., Mastead, A., \& Wagner, H. (1993). Optimism, perceived control over stress, and coping. European Journal of Personality, 27, 267-281.

Gillham, J.E. (Ed.). (2000). The science of optimism and hope: Research essays in honor of Martin E.P. Seligman. Philadelphia, PA: Templeton Foundation.

Herth, K. (1991). Development and refinement of an instrument to measure hope. Scholarly Inquiry for Nursing Practice: An International Journal, 5, 39 - 50.

Hinds, P.S. (1984). Inducing a definition of "hope" through the use of grounded theory methodology. Journal of Advanced Nursing, 9, 357-362.

Hollon, S.D., \& Kendall, P.C. (1980). Cognitive self-statements in depression: Development of an automatic thoughts questionnaire. Cognitive Therapy and Research, 4, 383-395.

Hu, L.-T., \& Bentler, P.M. (1998). Fit indices in covariance structure modeling: Sensitivity to underparameterized model misspecification. Psychological Methods, 3, 424-453.

Joreskog, K., \& Sorbom, D. (1996). LISREL 8: User's reference guide. Chicago: Scientific Software International.

Kline, R.B. (1998). Principles and practice of structural equation modeling. New York: Guilford.

Kobasa, S. (1979). Stressful life events, personality, and health: An inquiry into hardiness. Journal of Personality and Social Psychology, 37, 1-11.

Kwon, P. (2002). Hope, defense mechanisms, and adjustment: Implications for false hope and defensive hopelessness. Journal of Personality, 2002, 70, 207-213.

Levy, D.A. (1985). Optimism and pessimism: Relationships to circadian rhythms. Psychological Reports, 57, 1123-1126.

Magaletta, P.R., \& Oliver, J.M. (1999). The hope construct, will, and ways: Their relationship with self-efficacy, optimism, and general well-being. Journal of Clinical Psychology, 55, 539-551.

Malinchoc, M., Offord, K. P., \& Colligan, R.C. (1995). PSM-R: Revised Optimism-Pessimism Scale for the MMPI-2 and MMPI. Journal of Clinical Psychology, 51, 205-214. 
Marshall, G.N., Wortman, C.B., Kusulas, J.W., Hervig, L.K., \& Vickers, R.R. (1992). Distinguishing optimism and pessimism: Relations to fundamental dimensions of mood and personality. Journal of Personality and Social Psychology, 62, 1067-1074.

Maslow, A.H. (1970). Motivation and personality. (2nd ed.). New York: Harper \& Row.

Meninger, K. (1959). The academic lectures on hope. The American Journal of Psychiatry, 109, 481-491.

Mroczek, D.K., Sprio, A., Aldwin, C.M., Ozer, D.J., \& Bosse, R. (1993). Construct validation of optimism and pessimism in older men: Findings from the Normative Aging Study. Health Psychology, 12, 406-409.

Norem, J. K., \& Cantor, N. (1986). Defensive pessimism: Harnessing anxiety as motivation. Journal of Personality and Social Psychology, 51, 1208-1217.

Nowotny, M. L. (1989). Assessment of hope in patients with cancer: Development of an instrument. Oncology Nursing Forum, 16, 57-61.

Post-White, J., Ceronsky, C., Kreitzer, M. J., Nickelson, K., Drew, D., Mackey, K.W., Koopmeiners, L., \& Gutknecht, S. (1996). Hope, spirituality, sense of coherence, and quality of life in patients with cancer. Oncology Nursing Forum, 23, 1571-1579.

Robinson-Whelen, S., Kim, C., MacCallum, R.C., \& Kiecolt-Glaser, J.K. (1997). Distinguishing optimism from pessimism in older adults: Is it more important to be optimistic or not to be pessimistic? Journal of Personality and Social Psychology, 73, 1345-1353.

Rosenberg, M. (1965). Society and adolescent self-image. Princeton, NJ: Princeton University Press.

Rotter, J.B. (1954). Social learning and clinical psychology. Englewood Cliffs, NJ: Prentice-Hall.

Scheier, M.F., \& Carver, C.S. (1985). Optimism, coping, and health: Assessment and implications of generalized outcome expectancies. Health Psychology, 4, 219 - 247.

Scheier, M.F., \& Carver, C.S. (1992). Effects of optimism on psychological and physical well-being: Theoretical and empirical update. Cognitive Therapy and Research, 16, 201-228.

Scheier, M.F., Carver, C.S., \& Bridges, M.W. (1994). Distinguishing optimism from neuroticism (and trait anxiety, self-mastery, and self-esteem): A reevaluation of the Life Orientation Test. Journal of Personality and Social Psychology, 67, 1063-1078.

Seligman, M.E.P. (1991). Learned optimism. New York: Knopf.

Seligman, M.E.P., \& Csikszentmihalyi, M. (2000). Positive psychology: An introduction. American Psychologist, 55, 5-14.

Sherer, M., Maddux, J. E., Mercandante, B., Prentice-Dunn, S., Jacobs, B., \& Rogers, R.W. (1982). The self-efficacy scale: Construction and validation. Psychological Reports, 51, 663-671.

Smith, T.W., Pope, M.K., Rhodewalt, F., \& Poulton, J.L. (1989). Optimism, neuroticism, coping, and symptom reports: An alternative interpretation of the Life Orientation Test. Journal of Personality and Social Psychology, 56, 640-648.

Snyder. C.R. (1989). Reality negotiation: From excuses to hope and beyond. Journal of Social and Clinical Psychology, 8, 130-157.

Snyder. C.R. (1994). The psychology of hope: You can get there from here. New York: Free Press.

Snyder, C.R. (1995). Conceptualizing, measuring, and nurturing hope. Journal of Counseling and Development, 73, 355-360.

Snyder, C.R. (Ed.). (2000). The handbook of hope: Theory, measures, and applications. San Diego, CA: Academic Press.

Snyder, C.R. (in press). Hope theory: Rainbows in the mind. Psychological Inquiry.

Snyder, C.R., Harris, C., Anderson, J.R., Holleran, S.A., Irving, L.M., Sigmon, S.T., Yoshinobu, L., Gibb, J., Langelle, C., \& Harney, P. (1991). The Will and the Ways: De- 
velopment and validation of an individual-differences measure of hope. Journal of Personality and Social Psychology, 60, 570-585.

Snyder, C.R., Hoza, B., Pelham, W.E., Rapoff, M., Ware, L., Danovsky, M., Highberger, L., Rubinstein, H., \& Stahl, K.J. (1997). The development and validation of the Children's Hope Scale. Journal of Pediatric Psychology, 22, 399-424.

Snyder, C.R., Sympson, S.C., Michael, S.T., \& Cheavens, J. (2001). The optimism and hope constructs: Variants on a positive expectancy theme. In E. Chang (Ed.), Optimism and pessimism (pp. 101-125). Washington, DC: American Psychological Association.

Snyder, C.R., Sympson, S.C., Ybasco, F.C., Borders, T.F., Babyak, M.A., \& Higgins, R.L. (1996). Development and validation of the State Hope Scale. Journal of Personality and Social Psychology, 70, 321-335.

Staats, S.R., \& Stassen, M.A. (1985). Hope: An affective cognition. Social Indicators Research, $17,235-242$

Steiger, J.H. (1990). Structural model evaluation and modification: An interval estimation approach. Multivariate Behavioral Research, 25, 173-180.

Tucker, L.R., \& Lewis, C. (1973). A reliability coefficient for maximum likelihood factor analysis. Psychometrika, 38, 1-10. 